\title{
A Duo of Multiple Intelligence and Quality Education in China
}

\author{
Juju Wang \\ School of Foreign Studies \\ Qilu Normal University \\ Jinan, China 250013
}

\begin{abstract}
It is widely acknowledged that talent demand is crucial for social and educational development. Overseas and domestic educational researches are all concerned about the quality education. The theory of multiple intelligence was put forward by Howard Gardner can provide theoretical reference for China's education. This paper demonstrated the closely relation between multiple intelligence and China's educational reform with the hope of providing a new perspective for it.
\end{abstract}

Keywords-multiple intelligence; quality education; educational reform

\section{INTRODUCTION}

Nowadays, a country's integrated strength, international competitiveness and stage are closely related with its education which has obviously been the core force of a nation's development. Last decades have witnessed the rapid progress of China who issued a set of strategies like National Medium and Long-term plan for Education Reform and Development (2010-2020) and National Education Career Development the Twelfth Five-year Plan. The reform of education moved forward step by step, in which quality education's issue and implement was a big initiative. However, with the influence of exam-oriented education, there still is some shortcomings in the development of quality education, like the score and enrollment rate centered phenomenon.

Howard Gardner, the world famous psychologist in education found intelligence was various when he participated in the Project Zero of Harvard University. When it comes to different intelligence, different people are quite different. Even the "stupid kid" who has lower daily behavior ability than normal people, may transcend other ones in music or painting. In 1983, he put forward multiple intelligence that meets the needs of quality education.

Multiple intelligence is a breakthrough of traditional education concepts, and is consistent with China's quality education. The theory focuses on students' various intelligence development and points that score is not the only standard for students' achievement, yet the advantages as well as the disadvantages of various intelligence should

A phased achievement of the "Study on the Teaching Strategies for $U$ ndergraduates Based on Learning Style" of Shandong social sciences plan ning study program (16CZWJ55). be concerned and students' different intelligence developments should be respected. At the same time, multiple intelligence can efficiently guide our quality education which could achieve great and rapid progress with multiple intelligence evaluating standards and principles.

\section{OVERSEAS AND DOMESTIC RESEARCH Status}

Multiple intelligence was put forward by American educationist, and spread from America to the world quickly. So the research of it is early and abundant overseas, in which a series of experiments like colorful spectral project in American schools were launched in order to explore intelligence potential and enable the students to develop to the largest extent. In addition, the multiple intelligence key experimental schools were established, in which students can join in various activities aimed at developing intelligence potential. Educational scholars in other countries started to learn the multiple intelligence theories and use it as the guiding thought in educational reform.

Most educational reform aimed at the average students, and neglected the students in bad conditions like children with special needs who can be helped with multiple intelligence. This theory was used widely in the field of special education which has changed its defect-centered direction. Many handicapped children in South America obtained the educational opportunity through digital technology. The bad behaved students in traditional education in South Korea, Britain and America have presented huge progress using multiple intelligence to satisfy distinctive individual needs.

Domestic study on multiple intelligence began in the 1990s when it was introduced without deep understanding and application in China. There were increasing people who became interested and started to study the theory since $21 \mathrm{st}$ century. The scholars began combine it with their own conditions and got aspirations from the respect of multiple intelligence.

Shen Zhilong, the physical chemistry professor in institute of chemistry and physics in Peking industrial and commercial university, was the earlier educationist who contacted devoted himself into the study and application of multiple intelligence. When the theory's development was frustrated in China, Shen translated and published Gardner's 
Multiple Intelligence which arouse a stir and promoted the theory's development. After communicating with Gardner and participated in both overseas and domestic research meetings, Shen worked with Gardner together to advance the influence and application in Chinese education.

In 2000, Chinese education society worked on a practical research project referring Multiple Intelligence, Develop Students' Potential which was the key project of tenth five-year research plan. In 2002 international seminar Multiple Intelligence Development and Evaluation was held in Beijing in which many scholars discussed and communicated their ideas in multiple intelligence theories. In 2010 the international seminar with the topic of Multiple Intelligence and Global Educational Transition analyzed education from unique perspective and promoted multiple intelligence impacts on education.

Despite the increasing domestic development of multiple intelligence, it is still an imperfect theory without throughout research. Many researchers pointed out that the books about multiple intelligence have big gap between the overseas researches. A larger developing space should be explored combined with the domestic situation.

\section{THE GENERATION AND DEVELOPMENTS OF MULTIPLE INTELLIGENCE}

Gardner's research on child's art development and cognition was the basic of multiple intelligence generation, through which Gardner found human's intelligence was no single existed but with different intelligence independently existing. Some children with obvious disadvantages in some field have extraordinary performance in other fields. In 1983, Gardner put forward multiple intelligence theories in his book Frames of Mind and illustrated the existence and characteristics of 7 intelligence. The whole concept has never been changed through many researches afterwards, which exerted widespread influence in educational circle.

After testing the theory in the practice, Gardner created Multiple Intelligence in 1993, and Intelligence Re-framed in 1999. The theory began to be applied in other fields in the world and be developed with the combination of theory and the practice. In 2006, Gardner concluded the history, development and the predict in the future of the theory in the book Multiple Intelligences New Horizons. After that, Gardner joined related meetings, seminars and lectures in different areas of the world, and appealed more and more scholars.

\section{ENLIGHTENMENT OF MULTIPLE INTELLIGENCE}

\section{A. Enlightenment on Teachers}

Multiple intelligence has proven that everyone has their own potential, and this kind of educational concept should be armed with the teacher. Teachers should be aware that each student has potential to be success and change the old standard to evaluate the student by language and math centered logic. The student's shining points should be spotted by abandoning the concept that learning scores are the criterion. The language bad learner may be a talent in music or other skills.

Students' intelligence extent can be efficiently analyzed by multiple intelligence theories, and students' quality situation should be the principle for teaching plan. Teaching strategies should be adjusted further according to students' further development. Different students should be arranged with different teaching styles, which is a good case of teaching students in accordance of their aptitude. Students' intelligence is not only affected physically but also influenced by environment, society, technology etc. teachers should get rid of the old ideas and improves their own skills in order to adjust teaching for students' multiple intelligence progress.

Teachers should not only focus on the formalizing teaching scores, exploring students' multiple intelligence has more significance. When it comes to developing the strong items in multiple intelligence, teachers are the cooperators and helpers who may confront unpredictable challenges and be required for more qualities. Teachers should improve their own abilities and try to use their own strong intelligence to promote teaching and keep in touch with the developing pace of the education.

Educational reform cannot finish overnight, and teachers may face various restrictions like traditional teaching forms. Knowledge acquiring cannot be the only thing of teaching, positive emotions, thoughts and values should be input in the process of teaching. Each student is unique with his own strong intelligence which should be discovered by the teacher and integrated with the practice in order to realize learning's value.

Teachers' impact on the students is out of imagination, any tiny change may be transition in the students' life. In the progress of helping students multiple intelligence developing, teachers can improve their own abilities, which is a good opportunity of win-win.

\section{B. Enlightenment on Students}

Students are the core of education which should work from the students' perspective with positive and accurate viewpoints. The sing faceted evaluating system will impede students' development. Through multiple intelligence assessment, the intelligence situation of one's own can be handled and adjust learning pace and styles. All things in their being are good for something. After discovering their own outstanding intelligence, students will build confidence and take advantage of their own priority.

Rapid development of the society will bring big change in students' training styles which have the features of diversity and selectivity. Each student has specific learning style and method, and comprehensive talents can be created after finding their own interests and potentials.

\section{Enlightenment on Education}

Classroom teaching reform has been carried out for quite a long time, yet teaching concept has not been changed 
thoroughly. Only the superficial parts have been changed with many shortcomings as follows.

Teacher's leading part is over-stressed in the class, who controls the whole class like monodrama. While students are the audience who enjoy teachers show and speech without cooperation.

Classroom training pattern is still designed for the exam providing same standard for all students. Students' distinctions are neglected leading to the elimination of their positiveness and creativity.

The class is programmed by the teacher previously, and it is the teacher who pushes the class forward. High quality class should be pushed by both the students and the teacher.

Classroom teaching is crucial for the educational reform which could be guided by multiple intelligence. This theory can supplement the theoretic needs for the classroom teaching, and promote teachers' professional skill.

The long and tough process of educational reform is closely related with educational concepts change which is the base and premise for the education. Multiple intelligence connotations meet the requirements of educational reform, and reconsider the relation between teaching and learning. In the classroom, teaching cannot only be teacher's behavior but should be changed with learner's intelligence conditions. Learners are the objects been served in teaching which should be aimed at promoting learners' condition. Learning is a subjective process in which students' intelligence condition determined teaching quality.

Anyone has various intelligence with different levels, which should be considered and integrated in education. For the sake of the diversity and complexity of the intelligence, various teaching strategies should be implemented according to students' intelligence and learning conditions.

For the perspective of students' management, teacher is the manager in traditional teaching. Most of the students are managed and evaluated by the same criterion which is final scores which cannot reflect the distinction and peculiarity of students' intelligence. Plenty of the talents are obliterated by the imperfect educational system which should be reformed immediately.

\section{CONCLUSION}

The generation, development of the multiple intelligence was illustrated in this paper, as well as its influence and effects. The particular enlightenment for the teacher, students and education was analyzed, and we can conclude that quality education in China can be guided by the multiple intelligence theory. Quality education needs further research, which is required by our education policy which is experiencing deep reforming. Human intelligence development can improve and influence our education quality, and this is the breakthrough of this paper. Further reforming method and specific strategies are demanded in the new future.

\section{REFERENCES}

[1] Chorun-Shiuh Koong, Chi-Ying Wu, An Interactive Item Sharing Website for Creating and Conducting On-line Testing [J]. Computers and Education, 2010.

[2] Howard Gardner, Reflections on Multiple Intelligence: Myths and Messages [J]. Phi Delta Kappan, 1995.

[3] Howard Gardner, Frames of Mind: The Theory of Multiple Intelligences [M]. New York: Basic Books, 1983.

[4] Shen Zhilong, The Decade of Multiple Intelligence's Spread and Application in China [J]. Jiangsu Education Research, 2009.

[5] Shen Zhilong, The Generation, Development and Prospects of Multiple Intelligence [J]. Jiangsu Education Research, 2009. 